\title{
Restoration of Retinal Structure and Function after Selective Photocoagulation
}

\author{
Alexander Sher, ${ }^{1}$ Bryan W. Jones, ${ }^{2}$ Philip Huie, ${ }^{3,4}$ Yannis M. Paulus, ${ }^{3}$ Daniel Lavinsky, ${ }^{3,4}$ Loh-Shan S. Leung, ${ }^{3}$ \\ Hiroyuki Nomoto, ${ }^{3}$ Corinne Beier, ${ }^{1}$ Robert E. Marc, ${ }^{2}$ and Daniel Palanker ${ }^{3,4}$ \\ ${ }^{1}$ Santa Cruz Institute for Particle Physics, University of California, Santa Cruz, California 95064, ${ }^{2}$ Moran Eye Institute, University of Utah, Salt Lake City, \\ Utah 84132, ${ }^{3}$ Department of Ophthalmology, Stanford University, Stanford, California 94305, and ${ }^{4}$ Hansen Experimental Physics Laboratory, Stanford \\ University, Stanford, California 94305
}

CNS neurons change their connectivity to accommodate a changing environment, form memories, or respond to injury. Plasticity in the adult mammalian retina after injury or disease was thought to be limited to restructuring resulting in abnormal retinal anatomy and function. Here we report that neurons in the mammalian retina change their connectivity and restore normal retinal anatomy and function after injury. Patches of photoreceptors in the rabbit retina were destroyed by selective laser photocoagulation, leaving retinal inner neurons (bipolar, amacrine, horizontal, ganglion cells) intact. Photoreceptors located outside of the damaged zone migrated to make new functional connections with deafferented bipolar cells located inside the lesion. The new connections restored ON and OFF responses in deafferented ganglion cells. This finding extends the previously perceived limits of restorative plasticity in the adult retina and allows for new approaches to retinal laser therapy free of current detrimental side effects such as scotomata and scarring.

\section{Introduction}

Neural plasticity in the mammalian CNS underlies processes of learning, memory formation, and changes due to disease or injury. The retina is the beginning of the visual pathway and exhibits adult plasticity associated mostly with injury or disease (Jones et al., 2003), although some forms of adaptive plasticity have been reported (Baylor, 1987; Wade and Wandell, 2002; Dunn et al., 2007; Olveczky et al., 2007). It has been long accepted that the extensive changes in retinal circuitry triggered by disease or injury are negative, leading to abnormal retinal anatomy and function (Jones and Marc, 2005; Marc et al., 2007).

It was discovered recently that continuity of the photoreceptor layer in rabbit and rodent retina can be restored after selective photocoagulation (Busch et al., 1999; Paulus et al., 2008; Belokopytov et al., 2010). Unlike more intense conventional burns, selective photocoagulation destroys only photoreceptors and retinal pigment epithelium (RPE), leaving cells in the inner

Received Feb. 28, 2012; revised Feb. 21, 2013; accepted March 10, 2013.

Author contributions: A.S. and D.P. designed research; A.S., B.W.J., P.H., Y.M.P., D.L., L.-S.S.L., H.N., R.E.M., and D.P. performed research; A.S., B.W.J., D.L., C.B., and D.P. analyzed data; A.S. and D.P. wrote the paper.

This work was supported by Burroughs Wellcome Fund Career Award at the Scientific Interface, Pew Charitable Trusts Scholarship in the Biomedical Sciences, and National Institutes of Health Grant EY023020 - 01 (A.S.); Research to Prevent Blindness Career Development Award, The Edward N. \& Della L. Thome Memorial Foundation (B.W.J.); National Institute of Health Grants EY02576, EY015128, EY014800 Vision Core, and National Science Foundation Grant 0941717 (R.E.M.); National Institute of Health Grant EY18608 - 05, Air Force Office of Scientific Research Grant FA9550-10-1-0503, Department of Defense Grant W81XWH-12-10575, and Stanford University Bio-X Grant (D.P.). We thank K. Mathieson, M. Krause, and A. Ng for technical assistance, A. Litke, W. Dabrowski, P. Hottowy, K. Mathieson, and $S$. Kachiguine for technical development, and B.A. Wandell for comments on the manuscript.

D.P. holds a patent licensed from Stanford University to Topcon Medical Laser Systems. The remaining authors declare no competing financial interests.

Correspondence should be addressed to Alexander Sher, Santa Cruz Institute for Particle Physics, UC Santa Cruz, 1156 High Street, CA 95064. E-mail: sasha@scipp.ucsc.edu.

DOI:10.1523/JNEUROSCI.1044-12.2013

Copyright $\odot 2013$ the authors $\quad 0270-6474 / 13 / 336800-09 \$ 15.00 / 0$ retinal layers intact. After a few days, RPE coverage is restored and, after a few weeks, the photoreceptor layer regains its continuity (Paulus et al., 2008). The most likely origin of the photoreceptors filling the lesion is a shift of healthy photoreceptors from the adjacent untreated areas (Zwick et al., 2008). Although these results indicate that migrating photoreceptors can fill in the lesion, little is known about the extent of the functional restoration.

This study explores the extent of functional restoration of the retinal network, focusing on the synaptogenesis between migrating photoreceptors and the deafferented bipolar cells located inside the lesion and the extent of the functional restoration of the OFF and ON pathways (Dowling and Boycott, 1966; Kolb, 1979; Calkins et al., 1996). The restoration of normal retinal structure and responses would demonstrate the existence of constructive adult mammalian retinal plasticity after injury. Such plasticity has multiple significant implications. Many studies have relied on retinal laser lesions as a model for investigation of cortical plasticity (Wandell and Smirnakis, 2009), assuming that retinal function in the lesions is lost permanently. Restoration of retinal sensitivity in the lesions might affect the interpretation of these studies. Furthermore, the process of establishing new connectivity between photoreceptors and the inner retinal neurons is important for guiding studies aimed at restoring sight in degenerate retina through genetic manipulation of the existing or surgical reintroduction of new retinal cells (MacLaren et al., 2006). The effect of photoreceptor migration over the laser lesion opens the door to new clinical approaches to retinal photocoagulation therapy that would allow restoration of continuity of the photoreceptor layer, thereby avoiding the deleterious side effects of the current standard laser treatment: scotomata and retinal scarring.

This study used histology, computational molecular phenotyping, and multielectrode recordings of retinal activity to inves- 
tigate the healing process in the rabbit retina. We observed that after the selective photocoagulation, bipolar cells located inside the lesioned site and $\mathrm{ON}$ - and OFF-center ganglion cells above the lesion regained their light responses, indicating that the migrating photoreceptors formed new connections with the underlying retinal circuitry.

\section{Materials and Methods}

Retinal laser application. The PASCAL laser system (Topcon Medical Laser Systems) provided $532 \mathrm{~nm}$ optical radiation with a nominally flattop intensity profile. At the aerial image plane of the slit lamp microscope, the laser spots measured 200 and $400 \mu \mathrm{m}$ in diameter, with the laser intensity transition from $10 \%$ to $90 \%$ occurring over $6 \mu \mathrm{m}$. Pulse duration was maintained at $20 \mathrm{~ms}$. Laser power was titrated to produce ophthalmoscopically "barely visible" lesions, defined as a faint but clearly visible lightening of the fundus pigmentation (Jain et al., 2008). The power range for $200 \mu \mathrm{m}$ spot size was $60-90 \mathrm{~mW}$ and for $400 \mu \mathrm{m}$ spots, 150-200 mW. A single masked observer graded the clinical appearance of the laser lesions within $1 \mathrm{~min}$ after the treatment.

Thirty-seven male Dutch Belted rabbits (weight 2-3 kg) were used in accordance with the Association for Research in Vision and Ophthalmology Statement Regarding the Use of Animals in Ophthalmic and Vision Research after approval from the Stanford University Animal Institutional Review Board. The rabbits were anesthetized using ketamine hydrochloride ( $35 \mathrm{mg} / \mathrm{kg}$, i.m.), xylazine ( $5 \mathrm{mg} / \mathrm{kg}$, i.m.), and glycopyrrolate $(0.1 \mathrm{mg} / \mathrm{kg}, \mathrm{i} . \mathrm{m}$.) administered $15 \mathrm{~min}$ before the procedure. Pupillary dilation was achieved by 1 drop each of $1 \%$ tropicamide and $2.5 \%$ phenylephrine hydrochloride. Topical tetracaine $0.5 \%$ was instilled in the eye before the treatment.

Retinal histology and immunohistochemistry. For histology, 20 male rabbits were killed either $2 \mathrm{~d}$ or 2 months after treatment with a lethal dose of pentobarbital (Beuthenasia, $150 \mathrm{mg} / \mathrm{kg}$, i.v.) in the marginal ear vein. Eyes were enucleated and fixed in $1.25 \%$ glutaraldehyde/ $1 \%$ paraformaldehyde in cacodylate buffer, $\mathrm{pH} 7.2$, overnight at room temperature. The eyes were then postfixed in osmium tetroxide, dehydrated with a graded series of ethanol, processed with propylene oxide, embedded in an epoxy resin, and sectioned into $1-\mu \mathrm{m}$-thick sections. Samples were stained with toluidine blue and examined by light microscopy. For transmission electron microscopy (TEM), the tissue was cut into $100 \mathrm{~nm}$ sections using an ultramicrotome (Reichert-Jung Ultracut E; Leica) and stained with uranyl acetate and lead citrate. TEM micrographs were captured with a JEM-1400 microscope (JEOL).

Serial sections of the retina were examined, and at least four burns from two different animals were analyzed for each time point. By visually scanning the serial sections, the widest lesions corresponding to each burn were identified as corresponding to the center of the lesion.

For GFAP immunohistochemical analysis, samples were formalin fixed and embedded in paraffin. Four- to 5 - $\mu$ m-thick sections were then deparaffinized and immunohistochemistry was performed using antiGFAP antibody conjugated to fluorescein. The sections were also counterstained with DAPI. In addition, $6-12$ lesions were analyzed per setting in 6 male rabbits with the following time points: 1, 3, 7, and $14 \mathrm{~d}$ and 1, 2, 3 , and 4 months.

For cell proliferation tests, two rabbits (four eyes) were used. These rabbits were a subset of the six used for GFAP staining. Light laser burns were administered 7 and $3 \mathrm{~d}$ before enucleation (10 lesions per eye). BrdU labeling reagent ( $10 \mathrm{ml}$; Invitrogen) was infused slowly in the marginal ear vein $2 \mathrm{~h}$ before killing the animal. Eyes and control samples from small intestines were fixed in formalin, embedded in paraffin, and sectioned into 4- to 5- $\mu \mathrm{m}$-thick sections. Sections were then incubated with BrdU antibody and stained with horseradish peroxidase/diaminobenzidine. The sections were bleached with hydrogen peroxide to remove RPE pigment before light microscopy.

Computational molecular phenotyping. Fixed and embedded tissues were processed with computational molecular phenotyping (CMP). Two male rabbits were used in these experiments. Retinal neurons were classified by CMP as described previously (Marc and Jones, 2002) using an array of small molecule signatures (L-asparate, L[SCAP]-glutamate, gly- cine, L-glutamine, glutathione, GABA, taurine) in addition to antibodies targeting rod opsin and long-wavelength-sensitive opsin. Briefly, isolated eyes were fixed in $1 \%$ paraformaldehyde, $2.5 \%$ glutaraldehyde, $3 \%$ sucrose, and $0.01 \% \mathrm{CaCl}_{2}$, in $0.1 \mathrm{M}$ phosphate buffer, $\mathrm{pH}$ 7.4. Tissues were then resected, dehydrated in graded methanol and acetone, and embedded in epoxy resin. Tissues were then serial sectioned at $200 \mathrm{~nm}$ onto 12-spot Teflon-coated slides (Cel-Line; Fisher Scientific). Antibody exposure and silver intensification were performed using a silverintensification protocol described previously (Kalloniatis and Fletcher, 1993). Incubation of all antibodies generated against small molecular targets and opsins was performed overnight at room temperature and visualized with goat anti-rabbit secondary IgG coated with $1 \mathrm{~nm}$ gold (GE Healthcare Corporation) and silver intensified. Adobe Photoshop CS5 was used for final image generation.

Neural activity was assessed by detecting the ion-channel-mediated activity by probing permeation of the organic cation 1-amino-4guanidobutane (AGB). AGB permeates activated $\alpha$-amino-3-hydroxyl5 -methylisoxazole-4-propionic acid, kainate, and $N$-methyl-D-aspartate iGluR-gated channels as well as mGluR6-receptor-mediated channels on ON bipolar cells (Marc, 1999a; Marc, 1999b; Marc et al., 2005). These events are recorded as overall integrals of AGB flux through the channel revealing "snapshots" of neural activity (Marc, 1999a). Therefore, AGB renders a physiologic image of signaling of all neurons in the preparation. AGB signals are then multiplexed with the CMP data to reveal the extent of neural activity in the identified cell populations.

The AGB was prepared as described previously (Kalloniatis and Fletcher, 1993; Marc and Jones, 2002). In short, rabbits were anesthetized with a loading dose of ketamine hydrochloride $(35 \mathrm{mg} / \mathrm{kg}$, i.m.) and xylazine ( $5 \mathrm{mg} / \mathrm{kg}$, i.m.). The eye was topically anesthetized with proparacaine and dilated with $1 \%$ tropicamide and $2.5 \%$ phenylephrine hydrochloride. A standard three-port pars plana, partial vitrectomy was then performed and a $12 \mathrm{ml}$ syringe was filled with $\mathrm{O}_{2}$-saturated AGB reagent $(10 \mathrm{mg} / \mathrm{ml})$ warmed to $37^{\circ} \mathrm{C}$. The syringe containing AGB was attached to the infusion line and the contents infused into the eye over 30 $\mathrm{min}$. A flash lamp was positioned over the eye at a distance of 8 inches and a $1 \mathrm{~Hz}$ alternating yellow and blue light was flashed for $30 \mathrm{~min}$. The animal was killed by $1 \mathrm{ml}$ of Beuthanasia-D (a solution of pentobarbital sodium and phenytoin sodium commonly used in dogs for painless and rapid euthanasia) delivered by cardiac puncture and the experimental eye infused with freshly prepared paraformaldehyde/glutaraldehyde fixative. The eye was fixed overnight, dehydrated, and embedded as described above in CMP methods.

Sequential $1-\mu \mathrm{m}$-thick slices were made, stained with toluidine blue, and examined by light microscopy. The center of the lesion was defined when the defective area visible in the photographs reached its maximum width. At this point, $200 \mathrm{~nm}$ slices for CMP were made. It usually takes a few sections before the full-width block face cuts are obtained. This procedure resulted in CMP analysis in slices that were within a few micrometers from the center of the lesion.

Electrophysiology. As described above, pattern of lesions was performed in vivo in nine male Dutch Belted rabbits $2 \mathrm{~d}$ and 2 months before the experiment. Eyes were then enucleated under terminal anesthesia under dim red light. The anterior portion of the eye and vitreous body were removed and a $4 \times 4 \mathrm{~mm}^{2}$ piece of retina with $2-3$ lesions was peeled from sclera and choroid under infrared microscope. This procedure resulted in most of the RPE granules remaining with the retina. The retinal piece was placed on the electrode array (512 electrodes; $1.7 \mathrm{~mm}^{2}$ total area). During the experiment, the retina was perfused with oxygenated Ames' solution, $\mathrm{pH} 7.4$, and kept at $30^{\circ} \mathrm{C}$. A computer-controlled CRT monitor displaying visual stimulus was focused on the photoreceptor layer by microscope objective. The image was delivered from below with the light passing through the transparent electrode array and the retina before reaching photoreceptors. After the experiment, photographs of the retina on the electrode array were taken in the transmitted light. These photographs showed locations of the lesions visible through hypopigmentation of RPE over the lesion relative to the recording electrodes. In addition, the observed pattern of hypopigmented spots was verified against the known pattern of lesions. The position of the visual stimulus relative to the electrodes was also measured, allowing us to 
merge the spatial sensitivity profiles of the identified RGCs with the location of the lesions.

Voltage traces from individual electrodes were digitized at a $20 \mathrm{kHz}$ sampling rate and used in the subsequent analysis to find spike times of individual RGCs (Litke et al., 2004). A few hundred RGCs were typically identified in a single retinal piece. The responses of the RGCs were characterized through their spiketriggered average (STA) response to a white noise black and white binary spatiotemporal white noise visual stimulus (checker size: 80 $\mu \mathrm{m}$; frame frequency: $60 \mathrm{~Hz}$ ). For each identified RGC, the spatial sensitivity profile was characterized by isosensitivity contour. RGCs were classified as having ON- or OFF-set light sensitivity based on their STA time course (Litke et al., 2004).

Electrophysiological images (EIs) of an RGC consisted of voltage traces recorded on all 512 electrodes at the time of an RGC spike, and then averaged over all the spikes produced by the RGC (Petrusca et al., 2007). The location of the cell body was estimated by taking the center of mass of the EI voltage trace amplitudes on seven electrodes centered at the electrode with the largest signal.

\section{Results}

Continuity of the photoreceptor layer in

$200 \mu \mathrm{m}$ lesions can be completely restored over 2 months after selective photocoagulation, with the RPE layer being restored in a few days (Fig. 1; Busch et al., 1999; Paulus et al., 2008; Paulus et al., 2011). In this procedure, the laser power and pulse duration are adjusted to damage only the RPE and photoreceptor layer. The inner retinal layers remain intact, with no signs of cell death detected at various time points (from $1 \mathrm{~h}$ to 4 months) after the procedure (Paulus et al., 2008). No significant difference ( $p>$ $0.6)$ was found between the density of the inner nuclear layer cells within the lesion and in untreated areas for either acute or healed (2-month-old) lesions. The comparison was done in three acute and three healed lesions by counting the number of cells per 100 $\mu \mathrm{m}$ length of the retinal sections (toluidine blue staining). Highresolution imaging (Fig. 1C, TEM) of the healed lesion at 2 months revealed local synapses between photoreceptors and bipolar cells. The migrated photoreceptor exhibits normal nuclear anatomy with evidence of increased protein synthesis due to ribosomal upregulation, as well as normal ribbon synapses complete with vesicles. Nearby bipolar cell processes indicate local connection to the photoreceptor pedicle, as opposed to extended sprouting. This image does not exclude the possibility of the migrated photoreceptors also retaining their original synapses with bipolar cells outside of the lesion.

Functional consequences of the lesions were investigated using multielectrode recordings (Litke et al., 2004) of the rabbit retinal response to spatiotemporal white noise visual stimuli at various time points after photocoagulation. In each preparation, retinal activity was simultaneously recorded at the lesion and in the surrounding untreated retina. Each recording yielded several hundred identified RGCs, and their spatiotemporal properties were characterized through their STA response to a white noise stimulus (Chichilnisky, 2001). Recordings were performed at low photopic light levels. The resulting spatial sensitivity maps were
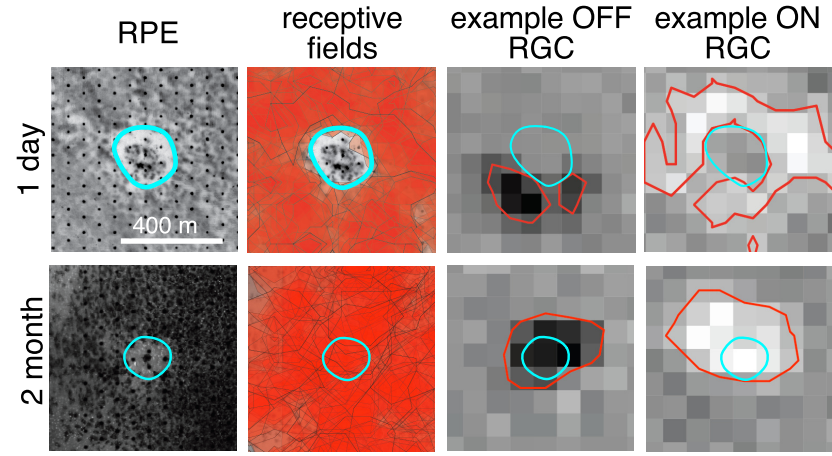

Figure 2. Restoration of retinal function after photocoagulation. Shown are $200 \mu \mathrm{m}$ lesions at $1 \mathrm{~d}$ (upper row) and 2 months (lower row) after the procedure. The first column on the left shows photographs of the retina on the multielectrode array taken after the recording. The regularly spaced black dots are electrodes and the grayish background shows RPE cells. The abnormal RPE zone is outlined by the cyan contour and indicates the lesion location. The second column from the left shows the photographs overlaid with the receptive fields of the recorded $\mathrm{RGCS}$. The receptive field of each $\mathrm{RGC}$ is represented by an isosensitivity contour uniformly filled with semitransparent red color. The third and fourth columns from the left show spatial sensitivity profiles of example OFF and ON RGCS, as revealed through their STA response to the spatiotemporal white noise. The abnormal RPE zone (cyan contour) and the isosensitivity contours (red) are shown.

registered with respect to the lesion locations by photographing the retina on the array after each recording.

The extent of functional restoration of the inner retinal neurons was assessed using CMP (Marc and Jones, 2002) combined with probing of glutamatergic-driven response to flickering light using an AGB marker (Marc, 1999a).

\section{Restoration of visual sensitivity}

Figure 2 compares acute 1-d-old and 2-month-old "barely visible" grade lesions made with $200-\mu \mathrm{m}$-diameter laser beam. The photographs of the retina on the electrode array (left panels) 

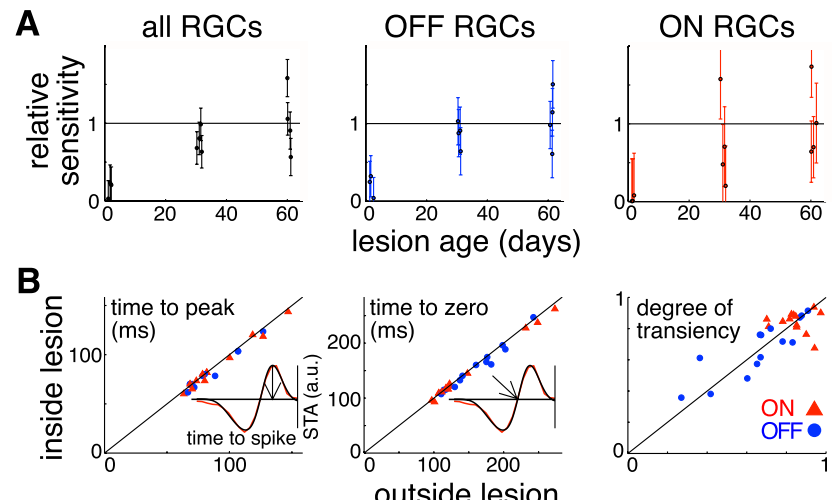

Figure 3. Restoration of retinal sensitivity and response kinetics in $200 \mu \mathrm{m}$ lesions. $\boldsymbol{A}$, Change in sensitivity over the lesion site with time. Sensitivity was calculated as a sum of STAs of all the RGCs recorded in a preparation. This sum within a lesion site was normalized to the average sensitivity over the healthy part of the retina. The uncertainties were estimated from the variability of the sensitivity over the healthy retinal regions. Plots for all RGCs and OFF- and ON-center RGCs are shown. Each point represents a separate lesion. Data from five retinal preparations are shown. $\boldsymbol{B}$, Comparison of response kinetics between the inside and outside of the lesion portions of receptive fields of individual $\mathrm{RGCs}$. Three aspects of the kinetics are shown: time to the first peak of the time course, time to the first zero crossing of the time course, and the degree of transiency measured through the relative areas of the first and second lobes of the time course. Inserts with a time course illustrate how the first two were measured. The red line in the example time course corresponds to the measured STA data and the smooth black line to the fit to that data. a.u. indicates arbitrary units. The plots include 27 cells that have receptive fields partially overlapping 42 -month-old lesions in 2 retinal preparations. OFF-center RGCs are shown with blue circles; ON-center RGCs are shown with red triangles.

taken in transmitted light help identify the location of the lesion (blue outline) relative to the electrode array through changes in the RPE pigmentation. In the first days after the lesion, the receptive fields of the recorded RGCs were unresponsive over the acute lesions, resulting in a blind spot in the lesion zone. After 2 months, the blind spot was absent in the $200 \mu \mathrm{m}$ lesion (Fig. 2). By 1 month, the average sensitivity over the lesion site measured through the STAs of the recorded RGCs approached that of the surrounding healthy retina and became indistinguishable $(p>$ 0.07 ) from it by 2 months after the photocoagulation (Fig. $3 A$ ). This restoration occurred for both ON and OFF RGCs and in every healed $200 \mu \mathrm{m}$ lesion located above the electrode array in our recordings, comprised of eight lesions across three retinal preparations. This measurement shows that the migrating photoreceptors had a functional connectivity to the inner retinal circuitry similar to that of the photoreceptors in the unaffected retinal area.

Details of connectivity between photoreceptors and various bipolar cell types play an important role in shaping the kinetics of retinal responses (Awatramani and Slaughter, 2000; DeVries, 2000; DeVries et al., 2006). Significant changes in response kinetics inside and close to the healed lesion indicate that this connectivity has been disturbed as a result of the photoreceptor migration. We quantified the kinetics of RGC responses through the STA time course, calculated as the average of the STA amplitude in the locations where the STA signal was above 3 SDs of the noise. The time course of each RGC was then fitted with a difference of low-pass filters (Chichilnisky and Kalmar, 2002) and three parameters were extracted from the fits. Each parameter reflects a different aspect of the cell's response assuming that the cell integrates information linearly over time. Time to the first peak of the STA characterizes the response latency, time to the first zero indicates the time it takes for the response to reach its maximum, and the degree of transiency predicts how close to the baseline the spike rate returns long after the presentation of the light intensity step. The degree of transiency was calculated as $1-$ $\operatorname{abs}(S) / S_{\text {abs }}$, where $S$ and $S_{\text {abs }}$ are integrals of the fitted time course and its absolute value, respectively. We did not observe a significant difference between the averages of each of these parameters over the cells that had receptive fields overlapping with the healed lesions and the cells that had receptive fields away from the lesions $(p>0.1)$. We then compared the kinetics of the individual RGC's visual responses driven by the photoreceptors that migrated inside the lesion to those that remained outside. A total of 27 RGCs that had their receptive fields overlapping with 4 healed 2 -month-old $200 \mu \mathrm{m}$ lesions were identified. The receptive field of each of the cells was divided into the inside- and outside-ofthe-lesion parts. STA time courses were calculated separately for each part. The two time courses were then fitted independently. Figure $3 B$ shows that the response kinetics were similar inside and outside of the healed lesions for each of the tested RGCs. Such similarity further strengthens the conclusion that the migrated photoreceptors had normal connectivity with the underlying retinal neurons, in particular with bipolar cells. Note that the data in Figure $3 B$ show that the responses observed within the lesioned areas did not arise from intrinsically photosensitive RGCs (Dacey et al., 2005; Berson, 2007; Schmidt et al., 2011). Intrinsic responses of intrinsically photosensitive RGCs have longer latencies (order of seconds) compared with photoreceptor-mediated responses. The measured latencies of the visual responses within the lesioned areas were $\sim 100 \mathrm{~ms}$, which is consistent with a photoreceptor-driven response.

Migrating photoreceptors could retain functional connectivity to their postsynaptic bipolar cells. In such an event, receptive fields that were originally adjacent to the lesion would extend into the lesioned area after the healing. Such a process would result in the enlarged receptive fields overlapping the healed lesion. Contrary to this prediction, we did not observe a statistically significant difference $(p=0.64)$ between the average receptive field sizes of the RGCs overlapping with the healed lesions (275 \pm 34 $\mu \mathrm{m})$ and the ones overlapping with the same number of the similarly sized circles mapped over the healthy retina $(299 \pm 38$ $\mu \mathrm{m})$. Both numbers represent (mean \pm SEM). The receptive field size of each cell was calculated as the diameter of a circle with the area equivalent to the 1- $\sigma$ contour of a two-dimensional Gaussian fitted to the STA frame containing the largest signal (Petrusca et al., 2007).

These results show that restoring the anatomical continuity of the photoreceptor layer after selective photocoagulation leads to restoration of retinal sensitivity at the coagulation site. Furthermore, this restoration takes place in the two major visual pathways sensitive to the ON- and OFF-set of light and does not lead to any major distortions in either spatial or temporal response properties of RGCs. For larger $(400 \mu \mathrm{m})$ lesions, the blind spot was greatly reduced at 2 months but did not disappear completely ( 2 lesions over 2 preparations). This suggests that the lateral distance the photoreceptors can shift during the healing process is limited to about $150 \mu \mathrm{m}$ (Busch et al., 1999; Paulus et al., 2008).

\section{Formation of new synapses between cone photoreceptors and bipolar cells}

Three different mechanisms can account for the observed restoration of visual sensitivity over the lesion site. The migrating photoreceptors could: (1) retain their connections to their old postsynaptic partners without forming new ones, (2) abandon their old postsynaptic partners and form entirely new connections with the bipolar cells in the lesioned region, or (3) retain 
A

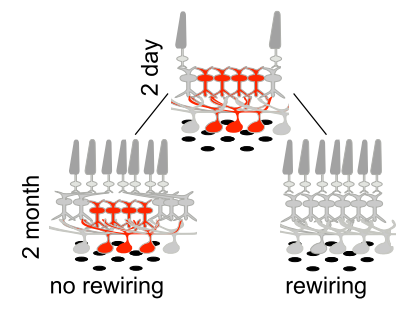

C
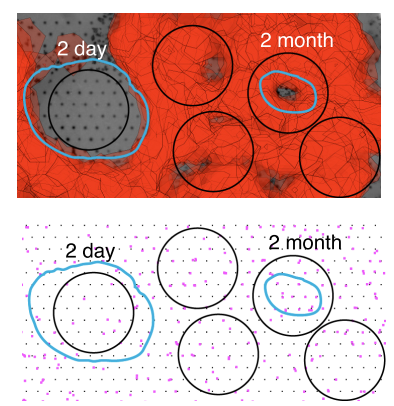

B

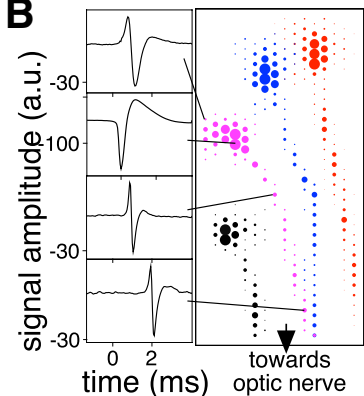

D
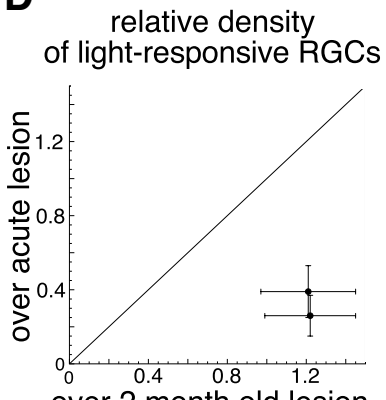

over 2 month old lesion

Figure 4. Restoration of retinal circuitry under the lesion. $\boldsymbol{A}$, Schematic of two outcomes of the photoreceptor migration: "no rewiring, " which leaves this circuitry without the input of photoreceptors located above it, and "rewiring, " which leads to restoration of retinal circuitry under the lesion. $\boldsymbol{B}$, Els of four cells from one retinal preparation. Sample voltage waveforms corresponding to dendritic, cell body, and axon locations are shown for one cell on the left. $\boldsymbol{C}$, Top: Photograph of retinal preparation with 2-d-old and 2-month-old lesions placed over the multielectrode array with the overlaid receptive field of the recorded RGCs. The RPE abnormality zones for the two lesions are outlined in cyan. Bottom: The soma locations of the RGCs that responded to visual stimulus (magenta dots). Two of the $400-\mu \mathrm{m}$-diameter black circles are centered on the two lesions and the other three are located randomly over the healthy retina. $D$, The comparison of densities of RGCs responsive to visual stimulus located within the $400-\mu \mathrm{m}$ diameter circle centered over the acute (1,2d) and healed ( 2 months) lesions for 2 retinas. The densities are relative to the $\mathrm{RGC}$ densities in the healthy regions of the same retinas.

some old connections and also form new ones. To distinguish between these possibilities, the density of light-sensitive RGCs was measured under the lesion site shortly after the photocoagulation procedure and after 2 months. Because of the vertical architecture of retinal connectivity, the density of the light-sensitive RGCs under the lesion is expected to decrease after the procedure. If no new connections are formed by the migrating photoreceptors (option 1 above), this reduced density should remain after the healing period. If new connections are formed (options 2 and 3 above), the density of light-responding RGCs above the lesions should increase. Figure $4 A$ depicts these two possible outcomes.

To measure the density of light-sensitive RGCs, we estimated positions of the cell bodies of the recorded RGCs. The electrical footprint of an RGC, called an EI (Petrusca et al., 2007), is an average electrical activity recorded on the multielectrode array when the RGC produces an action potential (see Materials and Methods). The EI provides information about spatial location of the RGC's cell soma, axonal trajectory, and, in some cases, the dendritic arbor (Fig. 4B).

The number of light-sensitive RGCs within 400 - $\mu$ m-diameter circles centered on the lesion sites was compared with the number of cells within the same size circles located over untreated parts of the retina. Figure $4 C$ shows one such measurement in a preparation in which 2-d- and 2-month-old $400 \mu \mathrm{m}$ diameter lesions were placed over the multielectrode array. The density of
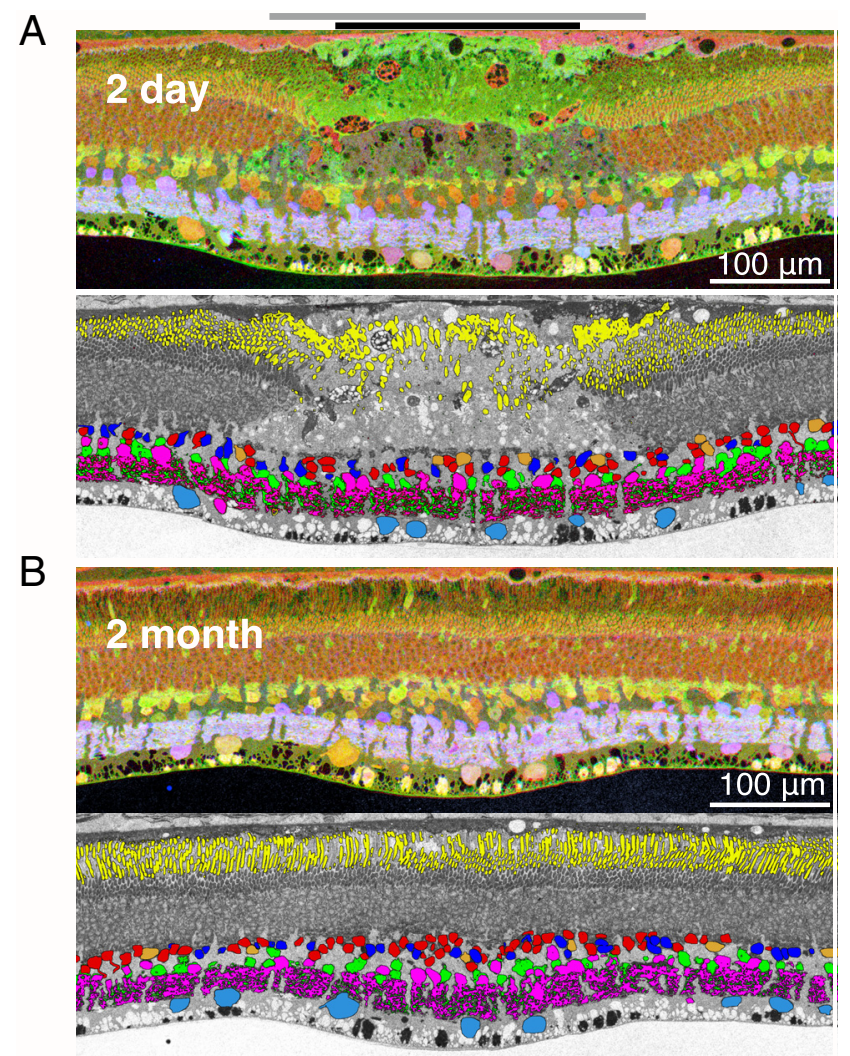

Figure 5. Restoration of the light-evoked activity in the inner retina. $\boldsymbol{A}$, Top: Section traversing the center of the 2-d-old lesion stained for glutamate (red), AGB (green), and GABA (blue). Bottom: Same section with the major retinal cell types identified through CMP clustering. The color coding is as follows: horizontal cells are shown in orange, hyperpolarizing cone bipolar and depolarizing rod bipolar cells in red, depolarizing cone bipolar cells in dark blue, GABAergic amacrine cells in magenta, glycinergic amacrine cells in green, and ganglion cells in light blue. The black bar at the top of the panel indicates the area of destroyed photoreceptors; gray bar shows the zone of surviving photoreceptors with detached or damaged outer segments. $\boldsymbol{B}$, Section traversing the center of the 2-month-old lesion. Same antibody staining and cell classifications as for the acute lesion are shown. Yellow color in both classification panels indicates location of rhodopsin.

light-responsive RGCs over acute lesions was 3 times lower than normal, but in the 2-month-old lesions, RGC density recovered to the same level as that found in untreated parts of the retina. This measurement was performed in two retinal preparations and yielded similar results (Fig. $4 D$ ). Note that the number of recorded RGCs did not vary significantly $(p=0.24$ and $p=0.29$ for the two preparations, respectively) between acute and healed lesions, indicating that the RGCs in the acute lesion site were active, but did not respond to the visual stimulus.

Additional evidence that the migrated photoreceptors were making new functional synaptic contacts to the bipolar cells over the lesion was obtained by performing AGB labeling of the photocoagulated retina exposed to flickering blue/yellow light in vivo. AGB permeates activated iGluR and mGluR6 channels and reveals glutamatergic neuronal activity in response to the light stimulus. Identities of individual cells were determined through CMP clustering. We identified hyperpolarizing and depolarizing bipolar cells, glycinergic and GABAergic amacrine cells, horizontal cells, and ganglion cells. Figure 5 shows CMP of the $200 \mu \mathrm{m}$ lesions at $2 \mathrm{~d}$ and 2 months after the photocoagulation. Two panels are shown for each time point: one summarizes the results of clustering and another shows overlay of three signals: 

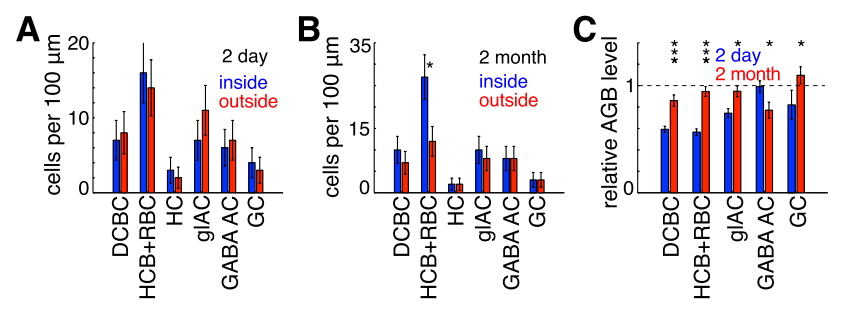

Figure 6. Presence of the neuronal cell types within acute and healed lesion sites. $\boldsymbol{A}$, Number of cells per $100 \mu \mathrm{m}$ length in 2-d-old lesion section shown in Figure 5A. Cell counts for the following six neuronal cell types are shown: depolarizing cone bipolar cells (DCBC), hyperpolarizing cone bipolar cells and rod bipolar cells $(H C B+R B C)$, horizontal cells $(H C)$, glycinergic amacrine cells ( $\mathrm{g} \mid \mathrm{AC})$, GABAergic amacrine cells (GABA AC), and ganglion cells (GC). For each of these cell types, blue (left) and red (right) bars show cell numbers inside and outside the lesioned area, respectively. $\boldsymbol{B}$, Number of cells per $100 \mu \mathrm{m}$ length in the 2-month-old lesion section shown in Figure 5B. Abbreviations and color (order) scheme are the same as in A. C, AGB levels for different cell types inside the lesions in the sections shown in Figure 5. Blue (left) and red (right) bars correspond to the AGB levels in the 2-d-old and 2-month-old lesions, respectively. For each cell type, the average AGB level among the cells within the lesion was normalized by the average AGB level calculated over the cells of the same type located outside the lesion in the same section. In all plots, ${ }^{*} p<0.05,{ }^{* *} p<0.01$, and ${ }^{* * *} p<0.001$. Error bars correspond to counting uncertainties $\left(\mathrm{n}^{1 / 2}\right)$ for $\boldsymbol{A}$ and $\boldsymbol{B}$ and SEM for $\boldsymbol{C}$.

L-glutamate, AGB, and GABA, marked with red, green, and blue, respectively.

At the $2 \mathrm{~d}$ time point (Fig. $5 \mathrm{~A}$ ), the photoreceptor layer was completely destroyed, whereas all of the inner retinal neuronal types were still present in the lesioned area. Because cells within the lesion exhibited normal small molecule signatures and the density of each cell type within the lesion was similar to that in the surrounding healthy retina (Fig. 6A), we conclude that the inner retinal cells within the lesion were not significantly affected. This confirms the previous histological assertion of highly selective destruction of photoreceptors based on toluidine blue staining. Outside of the lesion, the neurons, especially those in the inner nuclear layer, showed colocalization of glutamate (red) and AGB (green) signals, resulting in the yellow coloring of the cell bodies. Inside of the lesion, most of the inner nuclear layer cells showed glutamate signal but much lower AGB levels and appeared red in color, as one would expect, because this part of the retina no longer receives direct input from photoreceptors.

At 2 months, the retinal section across the center of the lesioned site (Fig. $5 B$ ) shows that the photoreceptors had filled in the damaged zone and that all of the major cell types are well represented inside the lesion (Fig. 6B). The light responsiveness of the cells in the inner nuclear layer is close to that of the cells outside of the lesion; that is, the AGB signal in the INL neurons is similar inside (Fig. 5B, center) and outside of the lesion compared with the stark differences observed in the 2-d-old lesion (Fig. 5A).

The light-evoked activity of inner-retinal neurons was further quantified by combining results of CMP clustering with AGB signaling. Average AGB concentration was measured in each of the major cell types inside the lesioned area and then normalized to the average AGB concentration of the same cell type in the surrounding tissue. Between the 2-d-old and 2-month-old lesions, this relative AGB concentration increased significantly for hyperpolarizing cone bipolar and rod bipolar cells $(p<0.001)$, depolarizing cone bipolar cells $(p<0.001)$, ganglion $(p<0.05)$, and glycinergic amacrine cells $(p<0.05)$ (Fig. $6 C)$. It did not increase for the GABAergic amacrine cells. The largest increase was measured in bipolar cells, which have the smallest dendritic trees of all these cell types and would therefore be the most affected by the destruction of the photoreceptors; that is, the larger portion of the wider field cells (ganglion and amacrine) would have inputs from outside the lesion. GABAergic amacrine cells are predominantly wide field and therefore would be the least affected by the photocoagulation of the small photoreceptor patch. The decrease in the AGB levels inside GABAergic amacrine cells in the healed lesion $(p<0.05)$ might be connected with real retinal restructuring or could be caused by a statistical fluctuation. Neither possibility can be excluded based on the data. We did not include horizontal cells in this analysis due to their small number. The apparent increase in the number of inner nuclear layer neurons in the CMP preparation (Fig. $5 B$ ) due to the increased number of hyperpolarizing cone and rod bipolar cells (Fig. 6C) in the healed lesion has not been confirmed statistically by histological analysis of a large number of lesions (Fig. 1; Paulus et al., 2008), and therefore should not be considered a typical occurrence.

The observed restoration of RGC visual sensitivity, physiological activity of the inner retinal neurons, and local synapses in the healed lesion (Fig. 1, TEM) strongly indicate that migrating photoreceptors make new functional connections to the bipolar cells that had their presynaptic photoreceptors destroyed by photocoagulation.

\section{Discussion}

We explored the extent of retinal functional restoration after selective destruction of the photoreceptors by laser photocoagulation in rabbits. Migration of the photoreceptors into the coagulated area resulted in restoration of visual sensitivity over the lesion site. The functional restoration was virtually complete for $200 \mu \mathrm{m}$ lesions. The $400 \mu \mathrm{m}$ lesions resulted in a reduced but persistent blind spot at 2 months. Both ON- and OFF-center RGCs exhibited the same degree of functional restoration. We detected no significant change in the receptive field size or response kinetics of the RGCs receiving inputs from the migrated photoreceptors. The RGCs located at the lesion regained light sensitivity after the healing. Inner retinal neurons at the lesion also normalized their integrated light-evoked activity as measured through AGB-mediated recording. These findings indicate that significant (and in some cases almost complete) restoration of retinal structure and function is possible through retinal plasticity evoked by the selective destruction of the photoreceptor layer in adult mammalian retina.

\section{Mechanism of the photoreceptor layer restoration}

The observed repopulation of the lesion with photoreceptors is most likely caused by photoreceptor redistribution in which healthy photoreceptors from outside of the lesion physically shift into the vacated space (Zwick et al., 2008). An alternative hypothesis would include large-scale neurogenesis of the new photoreceptors, which has never been observed in the adult mammalian retina (but see Osakada et al., 2007). To assess the extent of neurogenesis, we performed BrdU staining of retinal lesions at 3 and $7 \mathrm{~d}$ after photocoagulation (the time period with the fastest change in the lesion size). No BrdU expression was detected in the inner retina (data not shown), further supporting the migration hypothesis.

The mechanism of photoreceptor migration is unknown. One possibility is that it is mediated by Mueller cells that form a glial matrix filling the lesion in the photoreceptor layer shortly after photocoagulation, which then slowly contracts, bringing adjacent photoreceptor cell bodies with them. Activation of Mueller cells in and around the lesion and their dynamics can be observed through GFAP staining, as shown in Figure 7. Slight hypertrophy 


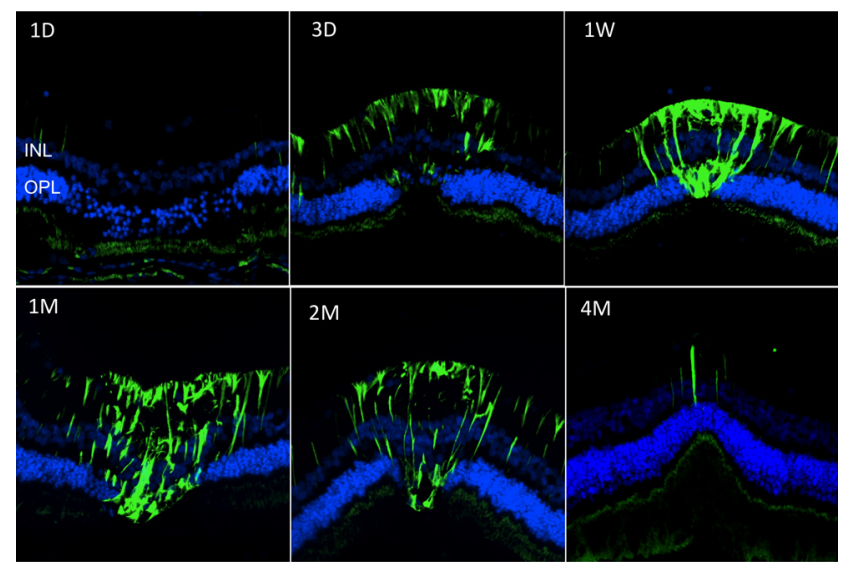

Figure 7. Mueller cell activation after photocoagulation. GFAP staining (green) shows activation of Mueller cells starting at $3 \mathrm{~d}(3 \mathrm{D})$ and ending between 2 and 4 months $(2 \mathrm{M}, 4 \mathrm{M})$ after selective photocoagulation. DAPI staining (blue) shows outer and inner nuclear layers.

of Mueller glia also can be noticed in the inner nuclear layer in Figure $5 A$, where it is manifested by the slightly enlarged space between the cell bodies in the inner nuclear layer.

\section{Restoration of retinal function and structure through synaptogenesis}

The observed restoration of visual sensitivity over the lesion site shows that the migrated photoreceptors have functional connectivity to the retinal circuitry. In the healthy retina, cone photoreceptors synapse onto both hyperpolarizing and depolarizing bipolar cells creating two major retinal pathways responsive to ON- and OFF-set of light. The restoration of both retinal pathways strongly indicates that the migrated cone photoreceptors have functional synapses onto both broad types of bipolar cells. Moreover, the observed visual sensitivity of the retinal ganglion cells located directly under the lesion, combined with the activation of inner retinal neurons located in the same area, suggests that the migrated photoreceptors synapse onto the bipolar cells that had their previous presynaptic photoreceptors destroyed by photocoagulation. Therefore, photoreceptors not only migrate in space and retain their photosensitivity, but they also form new synapses with bipolar cells, thereby restoring retinal structure and function at the lesion site. The TEM photographs show normal synapses of the photoreceptors that have migrated into the lesion. The details of the synaptic connections between cone photoreceptors and bipolar cells have a significant influence on the kinetics of the RGC light responses (Awatramani and Slaughter, 2000; DeVries, 2000; DeVries et al., 2006). The absence of significant differences in the RGC response kinetics between the areas inside and outside of the healed lesion indicates that the structure of the newly formed synapses between photoreceptors and bipolar cells is similar to that found in the healthy retina. Previous studies of injury-evoked retinal plasticity report abnormal photoreceptor synapse formation (Pinaud et al., 2006). It is possible that the difference in the outcomes is due to the new synapses formed by the healthy photoreceptors migrating into the lesion in the case of selective retinal photocoagulation, as opposed to compromised photoreceptors going through synaptic sprouting, as in the case of retinal detachment.

How close is the resulting circuitry to the original? The exact answer to this question would require extensive further anatomical and functional studies. For example, the present study does not address directly the possibility that the migrating photore- ceptors preserve some of their original connectivity to the bipolar and horizontal cells. We did not observe any anatomically obvious, human-fovea-like displacement between the photoreceptors and the cells in the inner nuclear layer. However, based on our measurements, we cannot exclude a possibility that some of the migrated photoreceptors retain their synapses with bipolar cells outside the lesion. One piece of evidence arguing against such remaining connections is that we did not observe significant enlargement of the receptive fields overlapping the healed lesions.

One of the hallmarks of negative retinal plasticity is somatic migration of various retinal cell types from their respective layers and changes in the inner retinal synaptic structure (Jones et al., 2003; Jones and Marc, 2005; Marc et al., 2007). We did not observe these well described traits of negative retinal plasticity: the major retinal cell types identified through CMP clustering remained in their respective layers and the overall pattern of the GABAergic and glycinergic amacrine cell processes was not disturbed throughout the healing process. This apparent absence of negative plasticity might be explained by a combination of the following factors. Fast photoreceptor migration and rewiring ensures that there is not enough time for the inner retinal rewiring and cell migration to take hold. In addition, the normal process of photoreceptor cell death in a retinal degenerative disease leaves some period of time (from hours to years) in which photoreceptor cells and their mitochondrial machinery have time to signal cell stress and potential inflammatory pathways. In photocoagulation, none of this is possible because the lesion is immediate and complete. In addition, the small size of the lesions allows at least some normal signaling, mostly through the wide field amacrine cells, to occur in the inner retina, thereby slowing down the negative plasticity. It would be interesting to test this hypothesis by observing larger lesions in which the photoreceptors do not fill the whole lesioned area. Over time, we would expect to observe negative plasticity in the persistent portion of the lesion. Even though we did not observe any obvious retinal restructuring, we cannot conclusively exclude a possibility of some changes in the inner retinal connectivity. Future functional and structural studies are needed to measure the exact extent of restoration of the complex retinal circuitry.

It is important to note that the functional measurements in this study were performed at photopic light levels; therefore, the degree to which rod photoreceptor pathway is restored remains to be investigated.

Laser photocoagulation of the retina provides a convenient model for studies of the mechanisms of retinal network response to injury or disease, potentially revealing processes responsible for its development and plasticity.

\section{Potential improvement of retinal laser therapy}

Since its introduction nearly 50 years ago, laser photocoagulation remains the standard of care for long-term therapy of several retinopathies. Laser treatment is thought to limit neovascularization by destroying retinal cells in the poorly perfused portions of the retina, thus limiting hypoxia and decreasing the production of angiogenic factors (Jennings et al., 1991; Matsumoto et al., 1994; Spranger et al., 2000; Sánchez et al., 2007). Because photoreceptors are the most numerous and metabolically active cells in the retina, pan-retinal photocoagulation for proliferative diabetic retinopathy involves the purposeful destruction of a significant fraction of photoreceptors (Little et al., 1970).

Although pan-retinal photocoagulation is a highly effective approach to halting angiogenesis, it results in permanent retinal scarring and decreased peripheral, color, and night vision 
(Higgins et al., 1986; Shimura et al., 2005). Focal and grid laser photocoagulation is an effective treatment of macular edema, but also causes scotomata and scarring (Morgan and Schatz, 1989; Schatz et al., 1991; Early Treatment Diabetic Retinopathy Study Research Group, 1995). Laser burns can enlarge postoperatively and cause choroidal neovascularization (Lewen, 1988; Lewis et al., 1990), subretinal fibrosis (Guyer et al., 1992; Rutledge et al., 1993; Lövestam-Adrian and Agardh, 2000), and additional visual field loss (Striph et al., 1988; Hudson et al., 1998; Ishiko et al., 1998; Mainster, 1999; Sinclair et al., 1999). Over time, loss of one class of retinal cells may, by trans-synaptic degeneration and associated inflammation, result in the loss of other retinal neurons (Stone, 1950; Birnbach et al., 1994) and RPE remodeling (Framme et al., 2009) or retinal remodeling (Marc et al., 2007).

The discovered retinal plasticity holds promise for improved laser treatment based on smaller spot size and selective destruction of photoreceptors while avoiding damage to the inner retinal neurons. This modification of current clinical therapy retains the postulated therapeutic effect through a reduction in the number of photoreceptors, but avoids permanent scarring and restores normal retinal function over the lesion sites, thus ameliorating or even eradicating the side effects associated with the current standard of care.

\section{References}

Early Treatment Diabetic Retinopathy Study Research Group 1995 Focal photocoagulation treatment of diabetic macular edema-relationship of treatment effect to fluorescein angiographic and other retinal characteristics at baseline: ETDRS report no. 19. Arch Ophthalmol 113:1144-1155. Medline

Awatramani GB, Slaughter MM (2000) Origin of transient and sustained responses in ganglion cells of the retina. J Neurosci 20:7087-7095. Medline

Baylor DA (1987) Photoreceptor signals and vision. Proctor lecture. Invest Ophthalmol Vis Sci 28:34-49. Medline

Belokopytov M, Belkin M, Dubinsky G, Epstein Y, Rosner M (2010) Development and recovery of laser-induced retinal lesion in rats. Retina 30: 662-670. CrossRef Medline

Berson DM (2007) Phototransduction in ganglion-cell photoreceptors. Pflugers Arch 454:849-855. CrossRef Medline

Birnbach CD, Järveläinen M, Possin DE, Milam AH (1994) Histopathology and immunocytochemistry of the neurosensory retina in fundus flavimaculatus. Ophthalmology 101:1211-1219. Medline

Busch EM, Gorgels TG, Van Norren D (1999) Filling-in after focal loss of photoreceptors in rat retina. Exp Eye Res 68:485-492. CrossRef Medline

Calkins DJ, Tsukamoto Y, Sterling P (1996) Foveal cones form basal as well as invaginating junctions with diffuse ON bipolar cells. Vis Res 36:33733381. CrossRef Medline

Chichilnisky EJ (2001) A simple white noise analysis of neuronal light responses. Network 12:199-213. Medline

Chichilnisky EJ, Kalmar RS (2002) Functional asymmetries in ON and OFF ganglion cells of primate retina. J Neurosci 22:2737-2747. Medline

Dacey DM, Liao HW, Peterson BB, Robinson FR, Smith VC, Pokorny J, Yau KW, Gamlin PD (2005) Melanopsin-expressing ganglion cells in primate retina signal colour and irradiance and project to the LGN. Nature 433:749-754. CrossRef Medline

DeVries SH (2000) Bipolar cells use kainate and AMPA receptors to filter visual information into separate channels. Neuron 28:847-856. CrossRef Medline

DeVries SH, Li W, Saszik S (2006) Parallel processing in two transmitter microenvironments at the cone photoreceptor synapse. Neuron 50:735748. CrossRef Medline

Dowling JE, Boycott BB (1966) Organization of the primate retina: electron microscopy. Proc R Soc Lond B Biol Sci 166:80-111. CrossRef Medline

Dunn FA, Lankheet MJ, Rieke F (2007) Light adaptation in cone vision involves switching between receptor and post-receptor sites. Nature 449: 603-606. CrossRef Medline

Framme C, Walter A, Prahs P, Regler R, Theisen-Kunde D, Alt C, Brinkmann R (2009) Structural changes of the retina after conventional laser pho- tocoagulation and selective retina treatment (SRT) in spectral domain OCT. Curr Eye Res 34:568-579. CrossRef Medline

Guyer DR, D'Amico DJ, Smith CW (1992) Subretinal fibrosis after laser photocoagulation for diabetic macular edema. Am J Ophthalmol 113: 652-656. Medline

Higgins KE, Meyers SM, Jaffe MJ, Roy MS, de Monasterio FM (1986) Temporary loss of foveal contrast sensitivity associated with panretinal photocoagulation. Arch Ophthalmol 104:997-1003. CrossRef Medline

Hudson C, Flanagan JG, Turner GS, Chen HC, Young LB, McLeod D (1998) Influence of laser photocoagulation for clinically significant diabetic macular oedema (DMO) on short-wavelength and conventional automated perimetry. Diabetologia 41:1283-1292. CrossRef Medline

Ishiko S, Ogasawara H, Yoshida A, Hanada K (1998) The use of scanning laser ophthalmoscope microperimetry to detect visual impairment caused by macular photocoagulation. Ophthalmic Surg Lasers 29:95-98. Medline

Jain A, Blumenkranz MS, Paulus Y, Wiltberger MW, Andersen DE, Huie P, Palanker D (2008) Effect of pulse duration on size and character of the lesion in retinal photocoagulation. Arch Ophthalmol 126:78-85. CrossRef Medline

Jennings PE, MacEwen CJ, Fallon TJ, Scott N, Haining WM, Belch JJ (1991) Oxidative effects of laser photocoagulation. Free Radic Biol Med 11:327330. CrossRef Medline

Jones BW, Marc RE (2005) Retinal remodeling during retinal degeneration. Exp Eye Res 81:123-137. CrossRef Medline

Jones BW, Watt CB, Frederick JM, Baehr W, Chen CK, Levine EM, Milam AH, Lavail MM, Marc RE (2003) Retinal remodeling triggered by photoreceptor degenerations. J Comp Neurol 464:1-16. CrossRef Medline

Kalloniatis M, Fletcher EL (1993) Immunocytochemical localization of the amino acid neurotransmitters in the chicken retina. J Comp Neurol 336: 174-193. CrossRef Medline

Kolb H (1979) The inner plexiform layer in the retina of the cat: electron microscopic observations. J Neurocytol 8:295-329. CrossRef Medline

Lewen RM (1988) Subretinal neovascularization complicating laser photocoagulation of diabetic maculopathy. Ophthalmic Surg 19:734-737. Medline

Lewis H, Schachat AP, Haimann MH, Haller JA, Quinlan P, von Fricken MA, Fine SL, Murphy RP. Choroidal neovascularization after laser photocoagulation for diabetic macular edema. Ophthalmology 97:503-510, 1990; discussion 510-501

Litke AM, Bezayiff N, Chichilnisky EJ, Cunningham W, Dabrowski W, Grillo AA, Grivich M, Grybos P, Hottowy P, Kachiguine S, Kalmar RS, Mathieson K, Petrusca D, Rahman A, Sher A (2004) What does the eye tell the brain?: Development of a system for the large-scale recording of retinal output activity. IEEE Transactions on Nuclear Science 51:1434-1440. CrossRef

Little HL, Zweng HC, Peabody RR (1970) Argon laser slit-lamp retinal photocoagulation. Trans Am Acad Ophthalmol Otolaryngol 74:85-97. Medline

Lövestam-Adrian M, Agardh E (2000) Photocoagulation of diabetic macular oedema-complications and visual outcome. Acta Ophthalmol Scand 78:667-671. CrossRef Medline

MacLaren RE, Pearson RA, MacNeil A, Douglas RH, Salt TE, Akimoto M, Swaroop A, Sowden JC, Ali RR (2006) Retinal repair by transplantation of photoreceptor precursors. Nature 444:203-207. CrossRef Medline

Mainster MA (1999) Decreasing retinal photocoagulation damage: principles and techniques. Semin Ophthalmol 14:200-209. CrossRef Medline

Marc RE (1999a) Mapping glutamatergic drive in the vertebrate retina with a channel-permeant organic cation. J Comp Neurol 407:47-64. CrossRef Medline

Marc RE (1999b) Kainate activation of horizontal, bipolar, amacrine, and ganglion cells in the rabbit retina. J Comp Neurol 407:65-76. CrossRef Medline

Marc RE, Jones BW (2002) Molecular phenotyping of retinal ganglion cells. J Neurosci 22:413-427. Medline

Marc RE, Kalloniatis M, Jones BW (2005) Excitation mapping with the organic cation AGB2+. Vis Res 45:3454-3468. CrossRef Medline

Marc RE, Jones BW, Anderson JR, Kinard K, Marshak DW, Wilson JH, Wensel T, Lucas RJ (2007) Neural reprogramming in retinal degeneration. Invest Ophthalmol Vis Sci 48:3364-3371. CrossRef Medline

Matsumoto M, Yoshimura N, Honda Y (1994) Increased production of transforming growth factor-beta 2 from cultured human retinal pigment 
epithelial cells by photocoagulation. Invest Ophthalmol Vis Sci 35:42454252. Medline

Morgan CM, Schatz H (1989) Atrophic creep of the retinal pigment epithelium after focal macular photocoagulation. Ophthalmology 96:96-103. Medline

Olveczky BP, Baccus SA, Meister M (2007) Retinal adaptation to object motion. Neuron 56:689-700. CrossRef Medline

Osakada F, Ooto S, Akagi T, Mandai M, Akaike A, Takahashi M (2007) Wnt signaling promotes regeneration in the retina of adult mammals. J Neurosci 27:4210-4219. CrossRef Medline

Paulus YM, Jain A, Gariano RF, Stanzel BV, Marmor M, Blumenkranz MS, Palanker D (2008) Healing of retinal photocoagulation lesions. Invest Ophthalmol Vis Sci 49:5540-5545. CrossRef Medline

Paulus YM, Jain A, Nomoto H, Sramek C, Gariano RF, Andersen D, Schuele G, Leung LS, Leng T, Palanker D (2011) Selective retinal therapy with microsecond exposures using a continuous line scanning laser. Retina 31:380-388. CrossRef Medline

Petrusca D, Grivich MI, Sher A, Field GD, Gauthier JL, Greschner M, Shlens J, Chichilnisky EJ, Litke AM (2007) Identification and characterization of a Y-like primate retinal ganglion cell type. J Neurosci 27:11019-11027. CrossRef Medline

Pinaud R, Tremere LA, De Weerd P (2006) Plasticity in the visual system: from genes to circuits. New York: Springer.

Rutledge BK, Wallow IH, Poulsen GL (1993) Sub-pigment epithelial membranes after photocoagulation for diabetic macular edema. Arch Ophthalmol 111:608-613. CrossRef Medline

Sánchez MC, Luna JD, Barcelona PF, Gramajo AL, Juarez PC, Riera CM, Chiabrando GA (2007) Effect of retinal laser photocoagulation on the activity of metalloproteinases and the alpha(2)-macroglobulin proteolytic state in the vitreous of eyes with proliferative diabetic retinopathy. Exp Eye Res 85:644-650. CrossRef Medline

Schatz H, Madeira D, McDonald HR, Johnson RN (1991) Progressive en- largement of laser scars following grid laser photocoagulation for diffuse diabetic macular edema. Arch Ophthalmol 109:1549-1551. CrossRef Medline

Schmidt TM, Do MT, Dacey D, Lucas R, Hattar S, Matynia A (2011) Melanopsin-positive intrinsically photosensitive retinal ganglion cells: from form to function. J Neurosci 31:16094-16101. CrossRef Medline

Shimura M, Yasuda K, Nakazawa T, Tamai M (2005) Visual dysfunction after panretinal photocoagulation in patients with severe diabetic retinopathy and good vision. Am J Ophthalmol 140:8-15. Medline

Sinclair SH, Alaniz R, Presti P (1999) Laser treatment of diabetic macular edema: comparison of ETDRS-level treatment with threshold-level treatment by using high-contrast discriminant central visual field testing. Semin Ophthalmol 14:214-222. CrossRef Medline

Spranger J, Hammes HP, Preissner KT, Schatz H, Pfeiffer AF (2000) Release of the angiogenesis inhibitor angiostatin in patients with proliferative diabetic retinopathy: association with retinal photocoagulation. Diabetologia 43:1404-1407. CrossRef Medline

Stone W (1950) Ocular injuries in the armed forces. J Am Med Assoc 142: 151-152. CrossRef Medline

Striph GG, Hart WM Jr, Olk RJ (1988) Modified grid laser photocoagulation for diabetic macular edema. The effect on the central visual field. Ophthalmology 95:1673-1679. Medline

Wade AR, Wandell BA (2002) Chromatic light adaptation measured using functional magnetic resonance imaging. J Neurosci 22:8148 8157. Medline

Wandell BA, Smirnakis SM (2009) Plasticity and stability of visual field maps in adult primary visual cortex. Nat Rev Neurosci 10:873-884. CrossRef Medline

Zwick H, Edsall P, Stuck BE, Wood E, Elliott R, Cheramie R, Hacker H (2008) Laser-induced photoreceptor damage and recovery in the high numerical aperture eye of the garter snake. Vis Res 48:486-493. CrossRef Medline 